\title{
Estrategia comunicacional de un proyecto territorial. La Investigación Enactiva Comunicacional (IEC) en el INTA, caso San Pedro-Baradero
}

\author{
Mariana Piola y Mariana Mascotti \\ Instituto Nacional de Tecnología Agropecuaria \\ mpiola@gmail.com / mmascotti@gmail.com
}

\begin{abstract}
Resumen
Este trabajo describe la metodología e implementación de la Estrategia Comunicacional (EC) del proyecto "Aportes para el crecimiento, la equidad y la sustentabilidad del territorio diversificado de los partidos costeros de San Pedro y Baradero", como caso bajo estudio en el marco de la investigación participativa y transdisciplinar propia de la metaperspectiva de la Comunicación Estratégica (CE) de la Escuela de Rosario. Describe el ambiente en que se desarrolló el caso a partir del cambio en la planificación de la extensión agropecuaria del INTA con el advenimiento de los proyectos regionales con enfoque territorial, incluyendo el sistema de medición comunicacional propuesto y el uso del Software IEC.
\end{abstract}

Palabras clave: comunicación estratégica, metodología, medición, estrategia

\section{Resumo}

Este artigo dá conta da experiência de uma Pesquisa Enactiva em Comunicação (IEC, pela sua sigla em espanhol) como uma modalidade de pesquisa participativa e transdisciplinar da meta-perspectiva da Comunicação Estratégica (CE) da Escola de Rosario. Descreve o ambiente em que se desenvolveu a partir da mudança no planejamento da extensão agrícola do INTA com o advento de projetos regionais com uma abordagem territorial, incluindo o proposto sistema de medição de comunicação. O IEC é um tipo de pesquisa de ação participativa que fornece um modo particular de construir uma estratégia de comunicação como um dispositivo de mudança. A metodologia e o produto da implantação da Estratégia Comunicacional (CS) dentro da estrutura da equipe interdisciplinar do projeto é descrita e o potencial do uso do Software IEC é mostrado.

Palavras chaves: comunicação estratégica, metodologia, medição, estratégia 
REVCOM | ISSN 2451-7836 | Año 4, \#8 | mayo de 2019 | Contribuciones | 0007

\section{Introducción}

La definición de una Estrategia Comunicacional $(\mathrm{EC})$ es central para un proyecto de desarrollo. Sin embargo, en general, hablar de estrategia comunicacional suele reducirse a la previsión de productos y espacios para difundir información cuando en realidad el despliegue de las dimensiones de una EC rebasan la información o la integran a los procesos socioculturales en los que los actores negocian significados y formas de hacer. Probablemente el tipo de racionalidad de los formularios con los que se elaboran los proyectos abone a este reduccionismo, -entendiendo que refieren a metas preestablecidas para el desarrollo de los procesos, valoración de productos aislados y una consideración de los cambios en términos casi exclusivamente cuantitativos-, entre otras características. Sobre tal problemática, consideramos que la reiteración de la operatoria se asienta principalmente en la escasa disponibilidad de metodologías de abordaje de la complejidad del fenómeno comunicacional.

En estrecha relación, este artículo propone dar cuenta de la experiencia situada de despliegue de la Investigación Enactiva Comunicacional (IEC) como modalidad de investigación participativa y transdisciplinar propia de la metaperspectiva de la Comunicación Estratégica (CE) de la Escuela de Rosario ${ }^{1}$ (Massoni, 2016), incluyendo el uso del Software IEC ${ }^{2}$ como parte del sistema de medición comunicacional.

Dicha medición se desarrolló en dos fases sucesivas del PID de la UNR "Comunicación Estratégica: indicadores comunicacionales en dimensiones múltiples"3. El caso es el de un proyecto de la Estación Experimental Agropecuaria INTA San Pedro. EI INTA en Argentina es un instituto de investigación y extensión agropecuaria que se propone:

\footnotetext{
1La Escuela de Comunicación Estratégica de Rosario es un núcleo de investigación y desarrollo enfocado en estudiar a los fenómenos comunicacionales desde una perspectiva específicamente comunicacional. El núcleo que inicia esta escuela es la tesis doctoral "Estrategias de comunicación rural: un modelo de abordaje de la dimensión comunicacional para el desarrollo sostenible entendido como cambio social conversacional" (Massoni, 2003). Ver http://escueladecomunicacionestrategica.org 2Denominación que toma la plataforma digital desarrollada por el PID que se amplía en la siguiente nota, y que permite registrar los indicadores comunicacionales de las estrategias implementadas así como generar de manera automática informes que dan cuenta de la marcha/evolución de la EC del proyecto. 3Se trata de dos proyectos de investigación y desarrollo sucesivos (PID 172 y PID 231) radicados en la Maestría de Comunicación Estratégica de la Universidad Nacional de Rosario (UNR). Los integrantes actuales del proyecto son: Sandra Massoni (Directora), Mariana Piola, Mariana Mascotti, Javier Spagnolo, Luciana Margherit y Mateo Bussi.
} 


\section{ReVcom \\ REVISTA CIENTIFICA DE LA REDCOM}

REVCOM | ISSN 2451-7836 | Año 4, \#8 | mayo de 2019 | Contribuciones | e007

"Impulsar la innovación y contribuir al desarrollo sostenible de un Sistema Agropecuario, Agroalimentario y Agroindustrial, competitivo, inclusivo, equitativo y cuidadoso del ambiente, a través de la investigación, la extensión, el desarrollo de tecnologías, el aporte a la formulación de políticas públicas y la articulación y cooperación nacional e internacional" (INTA, 2016).

En este entorno, los proyectos con enfoque territorial son la herramienta que organiza principalmente el componente de la extensión agropecuaria en las áreas de las estaciones experimentales, procurando la innovación en la ruralidad a través del entramado territorial. En esta planificación, las formas, productos y espacios de comunicación se tornan especialmente relevantes ya que son uno de los dispositivos clave de la transferencia tecnológica.

\section{La IEC en un proyecto con enfoque territorial}

Este trabajo describe la implementación de la EC del proyecto "Aportes para el crecimiento, la equidad y la sustentabilidad del territorio diversificado de los partidos costeros de San Pedro y Baradero", como caso bajo estudio del PID. Hacia fines de 2012 el Instituto Nacional de Tecnología Agropecuaria (INTA) implementó una nueva modalidad de planificar la extensión agropecuaria. Los proyectos centrados hasta el momento en las cadenas agroalimentarias clave de cada provincia, se transformaron en proyectos regionales con enfoque territorial (PRET). La estrategia institucional estuvo destinada a mejorar el abordaje de la complejidad territorial, con el objetivo de promover procesos de innovación para contribuir al desarrollo de los actores y sistemas productivos presentes en la región (Ledesma, S.; Cittadini, E., 2015). En ellos, la comunicación aparecía como un eje vinculado a la gestión territorial desde el inicio y la IEC ${ }^{4}$, es decir la plataforma digital desarrollada, encontraba una oportunidad propicia para su implementación ${ }^{5}$.

San Pedro y Baradero tienen una población de 92000 habitantes, y sus actividades productivas son la agropecuaria (tradición asociada a la fruticultura, horticultura extensiva y

4Refiere a la modalidad de modalidad de investigación propia y específica de la metaperspectiva de la Comunicación Estratégica de la Escuela de Comunicación Estratégica de Rosario. Al respecto ver "Avatares del comunicador complejo y fluido" (Massoni, 2016).

5La Comunicación Estratégica es una metaperspectiva para el abordaje comunicacional que el INTA ha implementado desde mediados de la década de 1980 en diferentes proyectos (Ejemplo: PAC 1989, Comunicación estratégica en Lechería 2010-2012, Comunicación estratégica en apicultura 2010-2012, entre otros). La propuesta innovadora de los PRET se presentó como una oportunidad de articularla con la plataforma de medición comunicacional desarrollada en el marco de los proyectos de investigación y desarrollo (PID).

"Estrategia comunicacional de un proyecto territorial. La Investigación Enactiva Comunicacional (IEC) en el INTA, caso San Pedro-Baradero" | Mariana Piola y Mariana Mascotti | https://doi.org/10.24215/2451-7836e007 | Pág. 3 


\section{REVCOm \\ REVISTA CIENTIFICA DE LA REDCOM}

REVCOM | ISSN 2451-7836 | Año 4, \#8 | mayo de 2019 | Contribuciones | e007

viveros, pero también grandes extensiones de cultivos agrícolas). Se suman las industrias importantes radicadas en la zona: Arcor, Papel Prensa, Refinerías de Maíz, Atanor. El turismo es otra fuente importante de ingresos. En lo que refiere a la presentacia de INTA, la Estación Experimental existe desde 1958 (Ruta 9, km 170), y se añaden la Agencia de Extensión Rural en San Pedro y la Oficina de desarrollo en Baradero.

Un equipo local integrado por investigadores, extensionistas, comunicadores y gerentes, había trabajado en la redacción inicial del proyecto de acuerdo al nuevo enfoque. En este primer documento institucional del PRET, aparecían tres problemáticas principales que fueron recuperadas como punto de partida del taller de elaboración de la Versión Técnica Comunicacional (VTC) $)^{6}$ en el marco de la IEC. Dichas problemáticas consistieron en 1) la baja competitividad y difícil sostenibilidad de las producciones intensivas y de menor escala, 2) Contaminación ambiental y degradación de los recursos naturales e incertidumbre sobre lacalidad/ inocuidad de los alimentos, 3) Débil articulación intra e interinstitucional (públicoprivada) para la puesta en marcha de proyectos consensuados.

La IEC es un tipo de investigación participativa que asume la multidimensionalidad del fenómeno comunicacional para operar transformaciones en las modalidades de vinculación intersubjetiva de las Matrices Socioculturales (MS) en la situación. "Su objetivo es propiciar el encuentro en la diversidad como un cambio social conversacional que enactúa" (Massoni, 2012). La enacción (Varela, 1988) es una alternativa a la idea de conocimiento como representación que implica entenderlo como emergencia situada: una particular vinculación entre sujeto-objeto que "trae mundos a la mano" (Ibídem). Desde esta comprensión, se plantea la IEC como un tipo de investigación que especifica los diferentes tipos de encuentro que ocurren en la comunicación, los procesos comunicacionales que implican (información, sensibilización, interacción, enacción comunicacional) y sus racionalidades. Entonces, propone una metodología con pasos que propician una participación cada vez más amplia y diversa de los actores del territorio de la investigación, en función del cambio que se pretende movilizar. La siguiente tabla sintetiza los siete pasos de la aplicación de la IEC realizados en este caso y los tiempos de implementación.

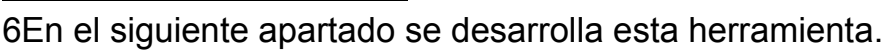


REVCOM | ISSN 2451-7836 | Año 4, \#8 | mayo de 2019 | Contribuciones | e007

Técnicas IEC implementadas en el proyecto

\begin{tabular}{|l|l|l|}
\hline \multicolumn{1}{|c|}{ Operación cognitiva } & \multicolumn{1}{|c|}{ Técnica } & \multicolumn{1}{|c|}{$\begin{array}{c}\text { Tiempo de } \\
\text { implementación }\end{array}$} \\
\hline 1. Diálogo de saberes & $\begin{array}{l}\text { Versión técnica comunicacional } \\
\text { (VTC) }\end{array}$ & Noviembre 2013 \\
\hline $\begin{array}{l}\text { 2. Determinación del tipo de encuentro } \\
\text { dominante }\end{array}$ & $\begin{array}{l}\text { Marcas de Racionalidad } \\
\text { comunicacional (MRC) }\end{array}$ & Noviembre 2013 \\
\hline $\begin{array}{l}\text { 3. Identificación de los agentes implicados } \\
\text { en la reconfiguración }\end{array}$ & $\begin{array}{l}\text { Mapeo comunicacional de } \\
\text { actores (MCA) }\end{array}$ & Junio 2014 \\
\hline $\begin{array}{l}\text { 4. Reconocimiento de los autodispositivos } \\
\text { colectivos }\end{array}$ & Matrices socioculturales (MS) & Julio 2014 \\
\hline $\begin{array}{l}\text { 5. Diseño y co-diseño de espacios y } \\
\text { productos comunicacionales }\end{array}$ & Árbol de soluciones (AS) & $\begin{array}{l}\text { Julio 2014 - Junio } \\
2018\end{array}$ \\
\hline $\begin{array}{l}\text { 6. Diseño y realización de investigación de } \\
\text { campo }\end{array}$ & Matrices de datos IEC & $\begin{array}{l}\text { No se } \\
\text { implementó9 }\end{array}$ \\
\hline $\begin{array}{l}\text { 7. Reconfiguración micro-macro social del } \\
\text { encuentro en la diversidad }\end{array}$ & $\begin{array}{l}\text { Plan operativo inicial de la } \\
\text { estrategia comunicacional }\end{array}$ & No se implementó \\
\hline
\end{tabular}

Basado en Massoni (2018)

E I Software IEC es una herramienta transversal que permite valorar analíticamente el estado y avances de los procesos comunicacionales considerando la multidimensionalidad y fluidez del fenómeno. Una medición que acompaña el despliegue de la EC mientras sucede y facilita la toma de decisiones en torno al cambio social conversacional que se busca promover.

\footnotetext{
7Se trata de reconocer, desde la comprensión de los sistemas complejos, el agrupamiento de actores respecto de sus lógicas de funcionamiento en torno a la situación. Este reconocimiento habilita recuperar la autoorganización en el despliegue de la Estrategia Comunicacional (EC)

8El reconocimiento y caracterización de Matrices Socioculturales (MS) implica un particular tipo de registro etnográfico que a partir de la identificación de rasgos comunes a un grupo de actores (trayectorias históricas, posicionamiento actual respecto de la problemática que aborda la estrategia comunicacional, modalidades del vínculo, compartidas y siempre situadas) los incorpora al desarrollo de la EC como dispositivo abierto y creciente de encuentro en la diversidad. En el siguiente apartado se desarrolla conceptualmente y en la Tabla 4 se exponen ejemplos de cómo se describen

9 No se realizó trabajo de campo. Se reconstruyó información con el marco de los talleres y recuperando la experiencia del área de Comunicación del INTA San Pedro.

10 Por una cuestión de extensión en este artículo no se desarrollan los alcances de cada una de las técnicas IEC. Los interesados en la profundización tanto de sus principios teórico-metodológicos como de las técnicas y herramientas de esta metaperspectiva comunicacional pueden consultar el Dossier temático de esta revista, como así también el trabajo de Massoni (2013).
} 


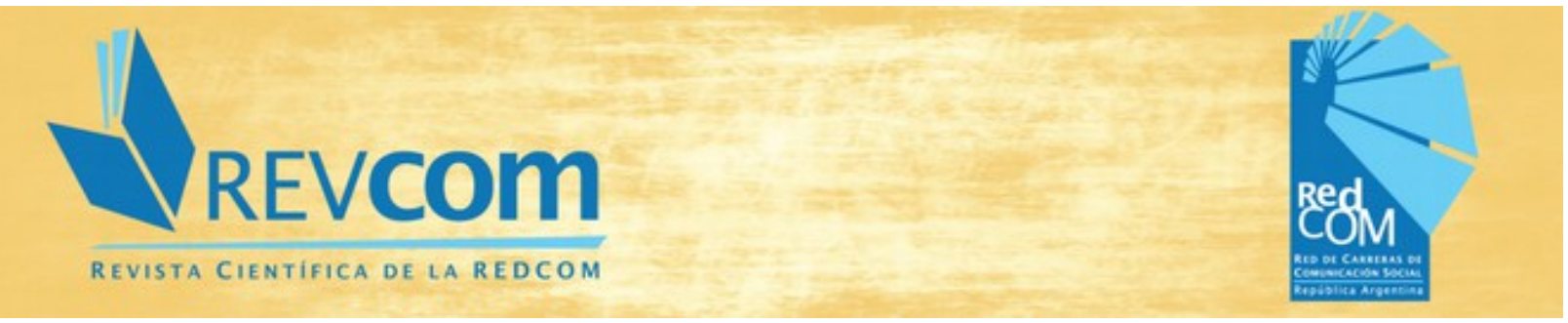

REVCOM | ISSN 2451-7836 | Año 4, \#8 | mayo de 2019 | Contribuciones | e007

\section{La VTC: el momento de concertar la problemática del proyecto}

La implementación de la metodología se realizó en talleres de dos días, en dos momentos diferentes, con participación del equipo interdisciplinario ${ }^{11}$.

Figura 2. Momentos de los talleres realizados para la construcción de la VTC.
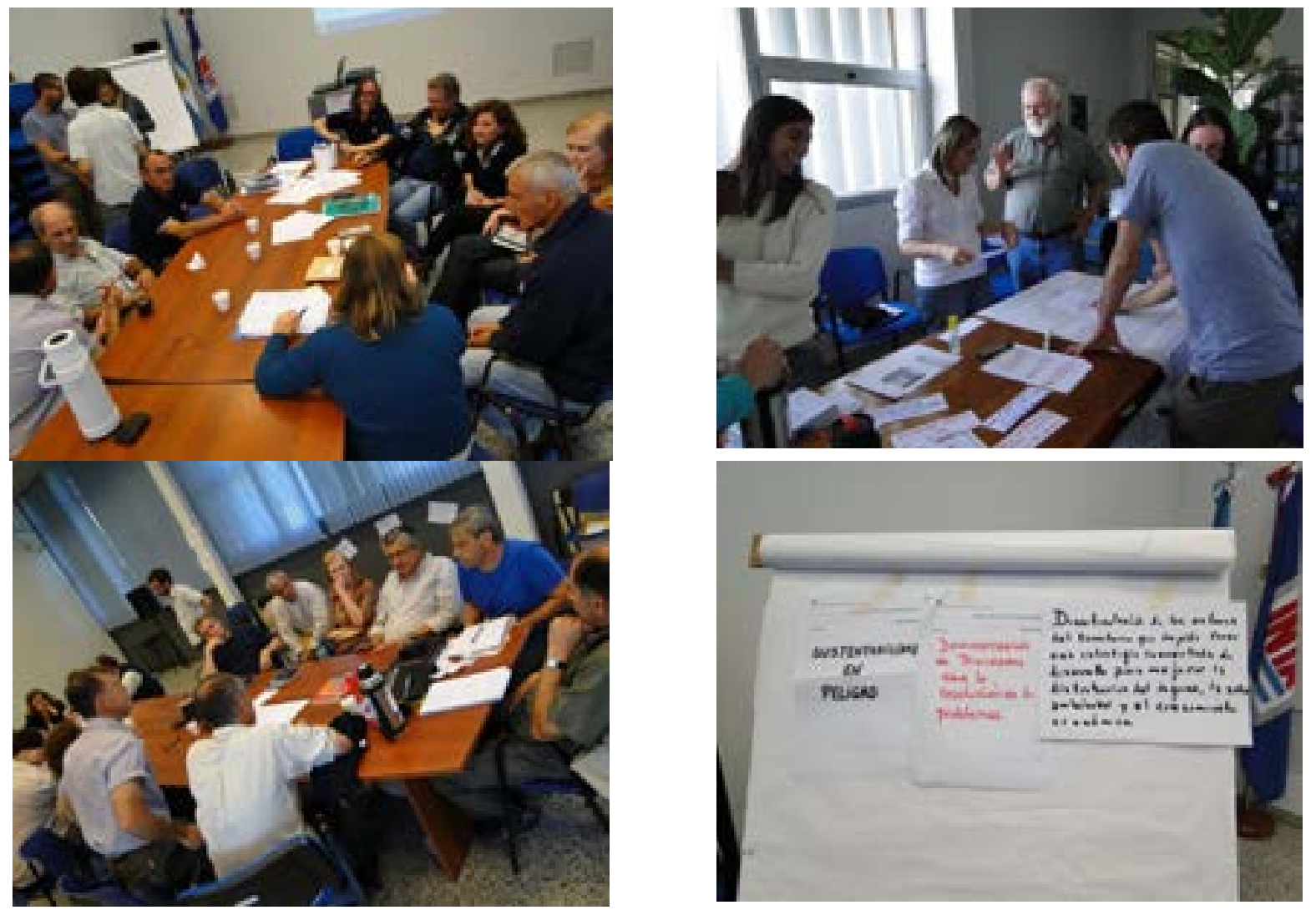

La VTC es una técnica específica de la IEC que supone la definición inicial de la problemática como obstáculo para la transformación buscada desde una organización o proyecto. Un equipo interdisciplinario define una frase núcleo que configura el territorio de la investigación comunicacional. Asentada en el diálogo de saberes como modalidad de trato con

11Participaron en el despliegue de la VTC investigadores y extensionistas de la Estación Experimental Agropecuaria San Pedro, provenientes de las ciencias agrarias (de diversas especialidades), de la administración, la comunicación, la antropología y la geografía. Ellos fueron: Osvaldo Valenzuela, Adolfo Paganini, Paganini, Nora Francescangeli, Juan José Glaría, Patricio Ros, Bernardo Andino, Paula Marcozzi, Laura Hansen, Verónica Liljesthrom, María José Cés, Adolfo Heguiabeheri, Rosana Gutiérrez, Ricardo Murray, Leandro Pagliaricci, Graciela Corbino, Gabriel Valentini, Luis Arroyo, Leonardo García, María Rosa Delprino, Héctor Martí, Carlos Zanek, Ignacio Paunero, Gonzalo Segade, José Czepulis, Mariel Mitidieri, Miguel Sangiacomo. Los facilitadores fueron: Mariana Mascotti, Mariana Piola, Lorena Peña, Javier Spagnolo y Bruno Menarvino. 


\section{$\checkmark$ REVCOm \\ REVISTA CIENTIFICA DE LA REDCOM}

REVCOM | ISSN 2451-7836 | Año 4, \#8 | mayo de 2019 | Contribuciones | e007

la complejidad, la VTC implica un despliegue en niveles (causas, consecuencias, síntomas) y dimensiones (componentes de la problemática) que se considera como una versión, que conversará con otras presentes en el territorio, y que la estrategia comunicacional irá articulando, buscando hacer "enactuar" nuevas acciones y sentidos compartidos en torno al problema. A partir del diálogo de saberes promueve reconsideraciones de las rutinas habituales en comunicación, evitando hacer encajar lo que se trae en la nueva planificación, propiciando sinergias más potentes. "(...) Es un instrumento de invención y de sintonización a la vez. Aquí también se juega su condición de mapa flexible y abierto" (Mascotti et al, 2014). En la Tabla 3 se incluye el despliegue de la VTC de este caso.

La concertación de la frase núcleo de la VTC -que da cuenta del obstáculo a la transformación que se pretende movilizar en el territorio- se sintetizó de la siguiente manera: Desarticulación de los actores que pone en peligro la sustentabilidad territorial. En su despliegue, se recuperaron los problemas reconocidos (Tabla 1) en cinco componentes (Económico, Ambiental, Sociocultural, Técnico-productivo e Institucional) y en niveles (causas, síntomas, consecuencias) (Tabla 3).

Tabla 3. VTC "Proyecto Regional para el desarrollo agropecuario del Noreste de Buenos Aires"

Proyecto "Aportes para el crecimiento, la equidad y la sustentabilidad del territorio diversificado de los partidos costeros de San Pedro y Baradero"

Versión Técnica Comunicacional - Herramienta VTC Sintética

Síntomas
Constante demanda de subsidios.

Decisiones inoportunas

Poca disponibilidad de personal especializado

Indiferencia y falta de participación en instancias de grupo

Falta de reconocimiento externo y desconsideración interna

Falta de participación en actividades grupales, colectivas y de toma de decisión

Actividades desarticuladas, superpuestas y discontinuadas

Desmotivación para seguir produciendo por no visualizar alternativas

Cada vez que hay cambios hay que rehacer vínculos (compartir, acordar)

La mayoría de los acuerdos son efímeros 


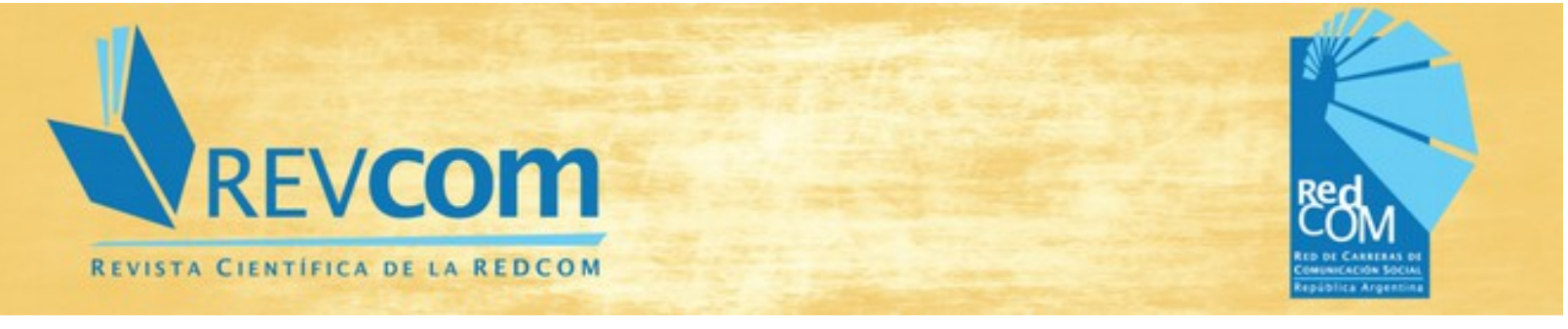

REVCOM | ISSN 2451-7836 | Año 4, \#8 | mayo de 2019 | Contribuciones | e007

\begin{tabular}{|c|c|}
\hline Consecuencias & $\begin{array}{l}\text { El subsidio aparece como la única opción de capitalizarse } \\
\text { Estancamiento productivo } \\
\text { Limitación en el crecimiento de los productores y su } \\
\text { escala } \\
\text { Imposibilidad de concretar proyectos asociativos o } \\
\text { similares } \\
\text { Falta de recursos para implementar algunas tecnologías } \\
\text { necesarias } \\
\text { Tareas que no se pueden realizar por la falta de personal } \\
\text { Pérdida de producción o ganancia } \\
\text { Conflicto de intereses } \\
\text { Contaminación de áreas urbanas } \\
\text { Falta de proyecto regional compartido } \\
\text { Mirada fragmentada de los problemas } \\
\text { Abandono de actividad y desocupación } \\
\text { Concentración productiva y reducción de los pequeños } \\
\text { productores } \\
\text { Migración de jóvenes de las actividades productivas } \\
\text { zonales } \\
\text { Desgaste, descreimiento y pérdida de motivación } \\
\text { (productiva e institucional) } \\
\text { Atomización de esfuerzos }\end{array}$ \\
\hline Frase núcleo de la VTC & $\begin{array}{l}\text { Desarticulación de los actores que pone en peligro la } \\
\text { sustentabilidad territorial }\end{array}$ \\
\hline Aspectos del problema & $\begin{array}{l}\text { Componente Económico } \\
\text { - limitado acceso financiero según competitividad y } \\
\text { escala } \\
\text { dificultad para la toma de decisiones en un } \\
\text { contexto cambiante y riesgoso } \\
\text { - dificultades con la mano de obra (no calificada, } \\
\text { inconstancia, etc) } \\
\text { Componente Ambiental } \\
\text { - dificultad para la toma de decisiones en un } \\
\text { contexto cambiante y riesgoso } \\
\text { - conflictividad en el ámbito periurbano y urbano } \\
\text { falta de incorporación o apropiación de las } \\
\text { Buenas prácticas agrícolas y de manufactura } \\
\text { Componente Sociocultural } \\
\text { - falta de reconocimiento del valor de la alteridad } \\
\text { - desconocimiento del trabajo de los otros }\end{array}$ \\
\hline
\end{tabular}




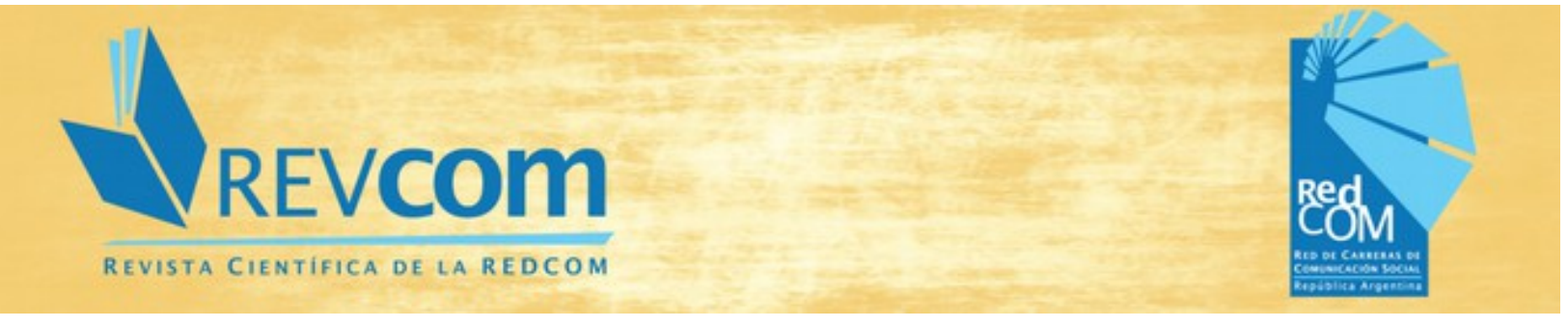

REVCOM | ISSN 2451-7836 | Año 4, \#8 | mayo de 2019 | Contribuciones | e007

\begin{tabular}{|c|c|}
\hline & $\begin{array}{l}\text { - diferente valoración de los problemas } \\
\text { Componente Técnico-productivo } \\
\text { - las tecnologías disponibles no siempre } \\
\text { contemplan variaciones de escalas } \\
\text { - Insuficiente validación de tecnologías que aporten } \\
\text { a un manejo racional ambiental y una visión } \\
\text { sistémica de las producciones del territorio } \\
\text { - las investigaciones estratégicas están } \\
\text { constantemente a menazadas por el } \\
\text { desfinanciamiento o los ritmos cambiantes de la } \\
\text { política institucional } \\
\text { - Componente Institucional } \\
\text { - escasas o malas experiencias de articulación } \\
\text { interinstitucional } \\
\text { dificultad para trabajar a partir de las diferencias } \\
\text { - políticas cambiantes o cortoplacistas en algunas } \\
\text { instituciones }\end{array}$ \\
\hline Causas próximas & $\begin{array}{l}\text { Créditos inadecuados en función a la falta de pago del } \\
\text { sector } \\
\text { Dificultad para el manejo de muchas variables } \\
\text { simultáneamente en la toma de decisiones } \\
\text { Visión transferencista y neutral de la tecnología } \\
\text { Falta de definición, implementación y cumplimiento de } \\
\text { normas } \\
\text { Falta de objetivos comunes entre actores del territorio, } \\
\text { escasas o malas experiencias de articulación } \\
\text { interinstitucional } \\
\text { Incertidumbre presupuestaria } \\
\text { Políticas cambiantes o cortoplacistas }\end{array}$ \\
\hline Causas básicas & $\begin{array}{l}\text { Falta de políticas de promoción crediticia y ordenamiento } \\
\text { territorial } \\
\text { Crecimiento urbano } \\
\text { El medioambiente aún no es visualizado como parte del } \\
\text { sistema productivo } \\
\text { Desconsideración de lo colectivo. }\end{array}$ \\
\hline
\end{tabular}

Basado en Massoni (2013)

La VTC opera el recorte de la situación que habilita el mapeo de actores, la identificación de los agentes clave en la reconfiguración del territorio de investigación (Figura 3). Los mismos se agrupan en Matrices Socioculturales (MS) según sus lógicas de funcionamiento en vinculación con la problemática (Tabla 4). 


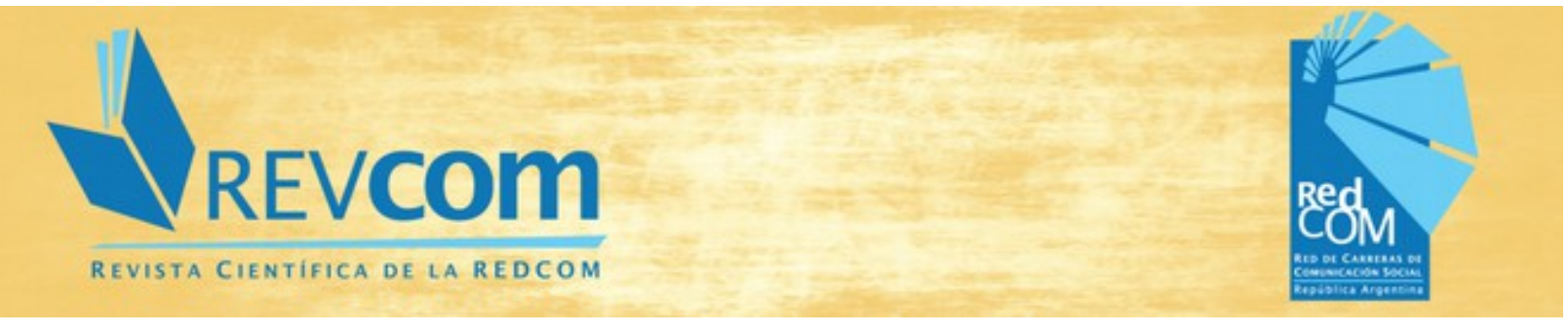

REVCOM | ISSN 2451-7836 | Año 4, \#8 | mayo de 2019 | Contribuciones | e007

Figura 3: Mapa de actores del Componente Ambiental

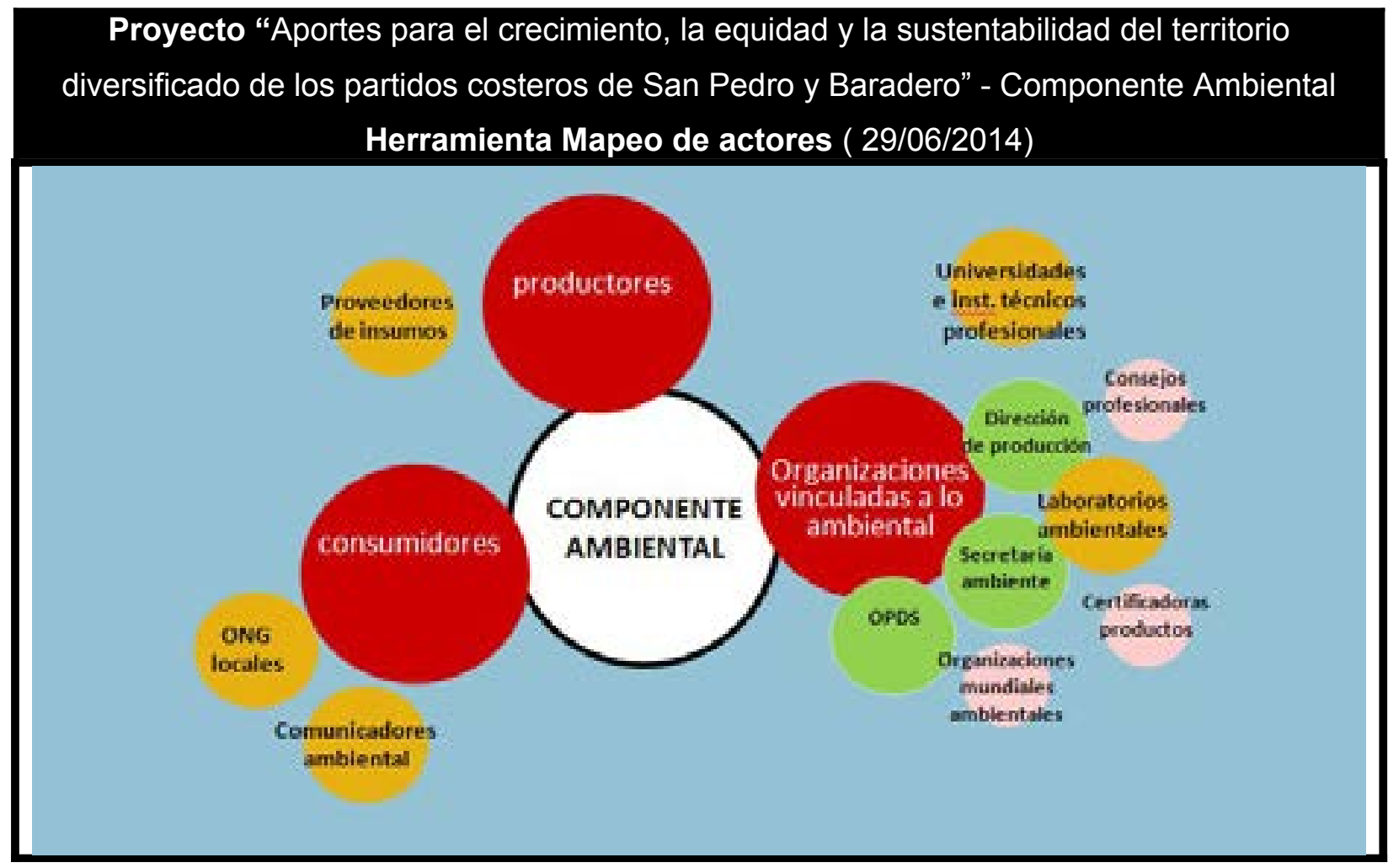

La descripción de una Matriz Sociocultural (MS) pretende recuperar la trayectoria de un sector en torno a la problemática mientras indica los límites y potencialidades del encuentro sociocultural posible. Se nombra por su modo de hacer en situación (por ejemplo: los que gestionan el desarrollo) enalteciendo lo vivo de la comunicación que nos ocupa en la IEC en contraposición a las habituales caracterizaciones predefinidas de los actores en los proyectos. De esta manera, se trata de un guión que habilita conversaciones generadoras de nuevas categorías y descripciones, surgidas del análisis interdisciplinario situacional. De esa escucha a la que nos convoca la IEC -no para responder sino para comprender- nos vuelven preguntas que interpelan los repertorios con los que solemos operar casi por inercia. Por ejemplo: ¿Qué hace un asesor técnico en la producción agropecuaria actualmente en esta situación? ¿Sus prácticas y modos de comunicación se diferencian de los modos de los vendedores de insumos? ¿En qué?. 


\section{Aavicom \\ REVISTA CIENTIFICA DE LA REDCOM}

REVCOM | ISSN 2451-7836 | Año 4, \#8 | mayo de 2019 | Contribuciones | e007

En el caso que estamos analizando, se reconocieron y caracterizaron once MS, de las cuales en la tabla se muestran cuatro (Tabla 4$)^{12}$.

Tabla 4. Matrices socioculturales ${ }^{13}$ del "Proyecto Regional para el desarrollo agropecuario del Noreste de Buenos Aires"

Proyecto "Aportes para el crecimiento, la equidad y la sustentabilidad del territorio diversificado de los partidos costeros de San Pedro y Baradero"

Herramienta Matrices Socioculturales ( 29/06/2014)

\begin{tabular}{|c|c|c|}
\hline & Descripción & Actores \\
\hline $\begin{array}{l}\text { Los que } \\
\text { producen } \\
\text { para } \\
\text { vender }\end{array}$ & $\begin{array}{l}\text { Les interesa producir para la venta, generar recursos } \\
\text { económicos y crecer. Les preocupan las condiciones } \\
\text { climáticas, los problemas con la mano de obra, los } \\
\text { controles y el acceso al crédito. } \\
\text { Los espacios de encuentro son principalmente las } \\
\text { reuniones técnicas, sectoriales. Los bares y algunas } \\
\text { reuniones grupales (de Cambio Rural por ejemplo) son } \\
\text { espacios de encuentro del sector. } \\
\text { Los agrupamientos en cámaras y cooperativas les } \\
\text { interesan para conseguir un beneficio que no } \\
\text { conseguirían solos. }\end{array}$ & $\begin{array}{l}\text { Productores } \\
\text { Productores } \\
\text { organizados (ej. } \\
\text { Cambio Rural) } \\
\text { Emprendedores } \\
\text { Cooperativas } \\
\text { (frutihortícola, apícolas, } \\
\text { FECOFE) } \\
\text { Cámaras }\end{array}$ \\
\hline $\begin{array}{l}\text { Los que } \\
\text { producen } \\
\text { para vivir }\end{array}$ & $\begin{array}{l}\text { Casi todos están conectados con la huerta. El vínculo } \\
\text { con la tierra y con lo artesanal es una característica de } \\
\text { este grupo. } \\
\text { Muchos viven aislados y valoran especialmente los } \\
\text { espacios de socialización. En este marco las ferias, por } \\
\text { ejemplo, son un lugar de encuentro privilegiado de esta } \\
\text { matriz. En general, su objetivo no es el salto de escala } \\
\text { productiva. Tienen una sensibilidad especial respecto de } \\
\text { la diversidad como parte de la existencia. La vida familiar } \\
\text { y la producción son un continuo, no están separadas. }\end{array}$ & $\begin{array}{l}\text { Agricultores familiares } \\
\text { Huerteros } \\
\text { Feriantes } \\
\text { Microemprendedores }\end{array}$ \\
\hline $\begin{array}{l}\text { Los que } \\
\text { gestionan } \\
\text { el } \\
\text { desarrollo }\end{array}$ & $\begin{array}{l}\text { Están interesados en la articulación de los actores para } \\
\text { lograr el objetivo de desarrollo territorial sin embargo, la } \\
\text { construcción de proyectos conjuntos muchas veces se } \\
\text { torna dificultosa. Toman decisiones movidos por una } \\
\text { lógica cortoplacista, dependiente de las coyunturas } \\
\text { políticas, institucionales y de los funcionarios de turno. } \\
\text { Se sienten desvalorizados en su función social, poco } \\
\text { reconocidos. Por sus características de organismos }\end{array}$ & $\begin{array}{l}\text { Técnicos de } \\
\text { organismos públicos: } \\
\text { Universidades } \\
\text { INTA, INTI, CONICET } \\
\text { Ministerio de } \\
\text { Desarrollo Social } \\
\text { PROSAP }\end{array}$ \\
\hline
\end{tabular}

$12 \mathrm{El}$ recorte obedece a que se trata de las MS vinculadas al AS que se desarrolla más adelante en el trabajo.

13 Se incluyen las principales MS con las cuáles se trabajó.

"Estrategia comunicacional de un proyecto territorial. La Investigación Enactiva Comunicacional (IEC) en el INTA, caso San Pedro-Baradero" | Mariana Piola y Mariana Mascotti | https://doi.org/10.24215/2451-7836e007 | Pág. 11 


\section{$\downarrow_{\text {REVCOm }}$ \\ REVISTA CIENTIFICA DE LA REDCOM}

REVCOM | ISSN 2451-7836 | Año 4, \#8 | mayo de 2019 | Contribuciones | e007

\begin{tabular}{|l|l|l|}
\hline & $\begin{array}{l}\text { técnicos, funcionan como mediadores en casos de } \\
\text { conflicto. Las mesas locales e intersectoriales son un } \\
\text { espacio de encuentro de esta matriz. }\end{array}$ & $\begin{array}{l}\text { Fundación ArgenINTA } \\
\text { Programas del Estado } \\
\text { SeCyT }\end{array}$ \\
\hline $\begin{array}{l}\text { Los que } \\
\text { gobiernan / } \\
\text { legislan }\end{array}$ & $\begin{array}{l}\text { Les interesa el rédito político de corto plazo. Tienen un } \\
\text { alto nivel de rotación que provoca el reinicio de los } \\
\text { procesos con frecuencia. Los actores con perfil más } \\
\text { técnico se encuentran, en general, alejados de los } \\
\text { niveles de decisión. Sus modos habituales de } \\
\text { comunicación tienen que ver con el debate, el diálogo, } \\
\text { las búsquedas de consenso. Participan en mesas, } \\
\text { asambleas. }\end{array}$ & $\begin{array}{l}\text { Gobiernos municipales } \\
\text { Gobierno provincial } \\
\text { Gobierno nacional } \\
\text { Concejales } \\
\text { Legisladores } \\
\text { provinciales } \\
\text { Mesas locales }\end{array}$ \\
\hline
\end{tabular}

\section{EI Árbol de Soluciones (AS): el momento de la desplegar la Estrategia Comunicacional} (EC)

En el árbol de soluciones, se proponen acciones comunicacionales para propiciar la reconfiguración del territorio en la dirección marcada por la estrategia comunicacional. Para esto se recuperan las lógicas de las MS analizadas y los procesos comunicacionales que se buscan promover en cada caso. A modo de ejemplo se presenta un segmento del árbol correspondiente al componente ambiental y sociocultural (Tabla 5).

Tabla 5. Árbol de soluciones, Componentes Ambiental y Sociocultural

Proyecto "Aportes para el crecimiento, la equidad y la sustentabilidad del territorio diversificado de los partidos costeros de San Pedro y Baradero"

Herramienta Árbol de soluciones ( 29/06/2014)

Componente Ambiental

\begin{tabular}{|c|c|c|c|}
\hline $\begin{array}{l}\text { Aspectos del } \\
\text { problema }\end{array}$ & $\begin{array}{l}\text { Matrices } \\
\text { socioculturales }\end{array}$ & $\begin{array}{l}\text { Proceso } \\
\text { comunicacional } \\
\text { a promover }\end{array}$ & Acciones \\
\hline \multirow{2}{*}{$\begin{array}{l}\text { dificultad para } \\
\text { la toma de } \\
\text { decisiones en } \\
\text { un contexto } \\
\text { cambiante y } \\
\text { riesgoso }\end{array}$} & $\begin{array}{l}\text { los que } \\
\text { gestionan el } \\
\text { desarrollo del } \\
\text { territorio }\end{array}$ & información & $\begin{array}{l}\text { Desarrollar un sistema de alerta de } \\
\text { condiciones climáticas y manejo de } \\
\text { cultivos asociados a las mismas }\end{array}$ \\
\hline & $\begin{array}{l}\text { los que } \\
\text { gestionan el }\end{array}$ & información & Boletín meteorológico mensual y diario \\
\hline
\end{tabular}

"Estrategia comunicacional de un proyecto territorial. La Investigación Enactiva Comunicacional (IEC) en el INTA, caso San Pedro-Baradero" | Mariana Piola y Mariana Mascotti | https://doi.org/10.24215/2451-7836e007 | Pág. 12 


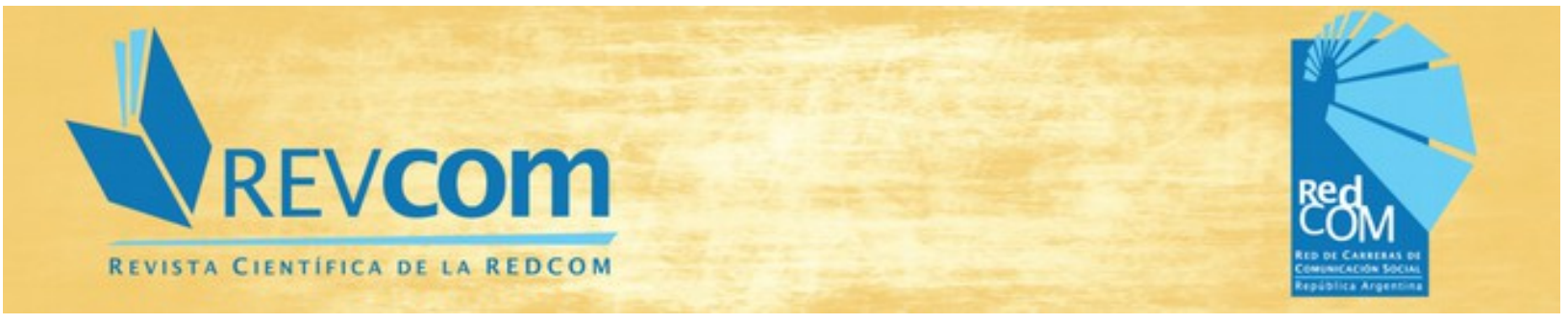

REVCOM | ISSN 2451-7836 | Año 4, \#8 | mayo de 2019 | Contribuciones | e007

\begin{tabular}{|c|c|c|c|}
\hline & \multirow[b]{2}{*}{$\begin{array}{l}\text { desarrollo del } \\
\text { territorio } \\
\text { los que } \\
\text { producen para } \\
\text { vender }\end{array}$} & & $\begin{array}{l}\text { Distribución de información relevante qu } \\
\text { llega al INTA } \\
\text { Charlas con panoramas agroclimáticos }\end{array}$ \\
\hline & & sensibilización & $\begin{array}{l}\text { Incluir un componente vinculado al } \\
\text { "Cambio climático" en la Vidriera } \\
\text { tecnológica para escuelas } \\
\text { Organizar charlas sobre problemas } \\
\text { climáticos } \\
\begin{array}{l}\text { Producir una serie de videos cortos sobr } \\
\text { problemas climáticos para las redes } \\
\text { sociales }\end{array}\end{array}$ \\
\hline & $\begin{array}{l}\text { los que } \\
\text { gestionan el } \\
\text { desarrollo del } \\
\text { territorio }\end{array}$ & sensibilización & $\begin{array}{l}\text { Generar espacios de trabajo y discusión } \\
\text { sobre escenarios de riesgo climático }\end{array}$ \\
\hline \multirow{3}{*}{$\begin{array}{l}\text { conflictividad } \\
\text { en el ámbito } \\
\text { periurbano y } \\
\text { urbano }\end{array}$} & \multirow{3}{*}{$\begin{array}{l}\text { los que } \\
\text { gobiernan } \\
\text { /legislan }\end{array}$} & sensibilización & $\begin{array}{l}\text { Organizar un taller de ordenamiento } \\
\text { territorial con actores pertenecientes a } \\
\text { distintos ámbitos de decisión en San } \\
\text { Pedro }\end{array}$ \\
\hline & & participación & $\begin{array}{l}\text { Participar activamente en las mesas } \\
\text { intersectoriales, foros de vecinos, de } \\
\text { productores y ambientalistas }\end{array}$ \\
\hline & & participación & $\begin{array}{l}\text { Elaboración de un proyecto de } \\
\text { ordenamiento territorial junto a otros } \\
\text { sectores. }\end{array}$ \\
\hline $\begin{array}{l}\text { falta de } \\
\text { incorporación o } \\
\text { apropiación de } \\
\text { las Buenas } \\
\text { prácticas } \\
\text { agrícolas y de } \\
\text { manufactura }\end{array}$ & $\begin{array}{l}\text { los que } \\
\text { producen para } \\
\text { vender } \\
\\
\text { los que } \\
\text { producen para } \\
\text { vivir }\end{array}$ & $\begin{array}{l}\text { sensibilización / } \\
\text { participación }\end{array}$ & $\begin{array}{l}\text { Organizar talleres para trabajar la } \\
\text { responsabilidad del productor en la } \\
\text { producción de alimentos (buenas } \\
\text { prácticas agrícolas en horticultores de } \\
\text { Baradero y de manufactura para } \\
\text { elaboradores de "Frutos de la tierra...") } \\
\text { Acompañamiento técnico en Buenas } \\
\text { prácticas de manufactura a elaboradore } \\
\text { de la agricultura familiar y entrenamient } \\
\text { para cumplimiento de norma }\end{array}$ \\
\hline
\end{tabular}

"Estrategia comunicacional de un proyecto territorial. La Investigación Enactiva Comunicacional (IEC) en el INTA, caso San Pedro-Baradero" | Mariana Piola y Mariana Mascotti | https://doi.org/10.24215/2451-7836e007 | Pág. 13 


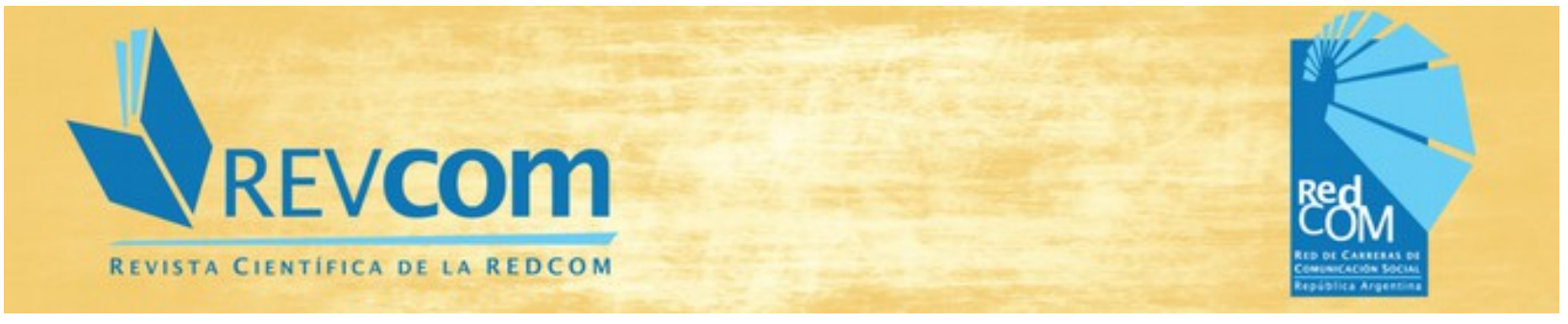

REVCOM | ISSN 2451-7836 | Año 4, \#8 | mayo de 2019 | Contribuciones | e007

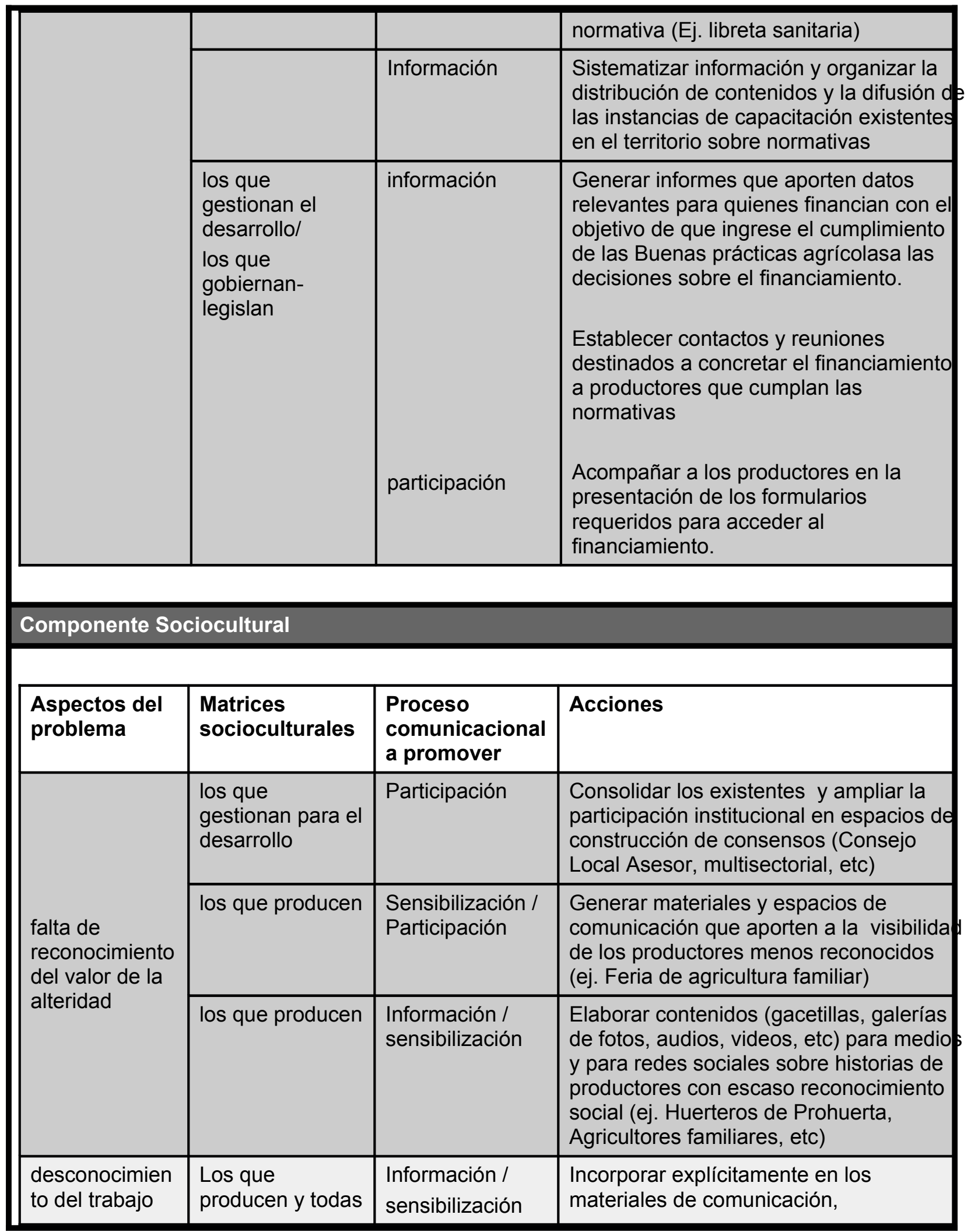

"Estrategia comunicacional de un proyecto territorial. La Investigación Enactiva Comunicacional (IEC) en el INTA, caso San Pedro-Baradero" | Mariana Piola y Mariana Mascotti | https://doi.org/10.24215/2451-7836e007 | Pág. 14 


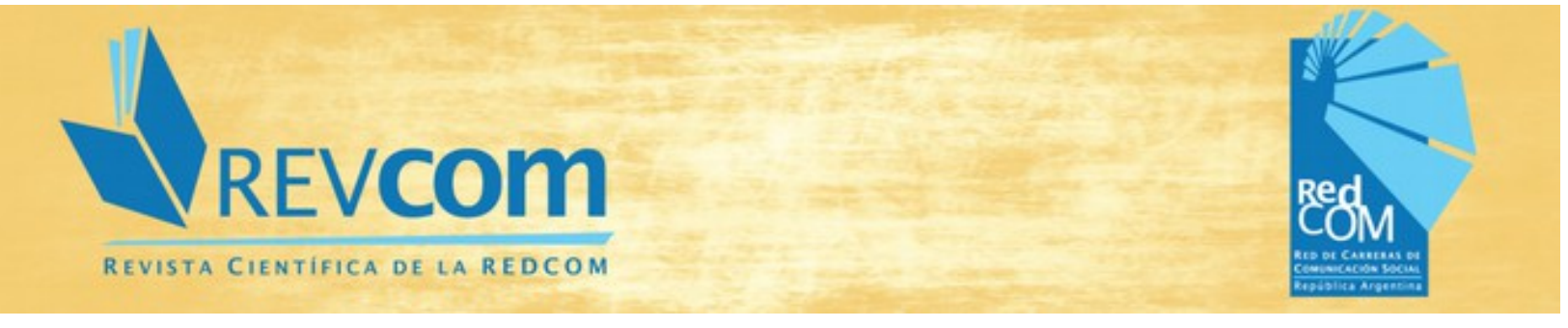

REVCOM | ISSN 2451-7836 | Año 4, \#8 | mayo de 2019 | Contribuciones | e007

\begin{tabular}{|c|c|c|c|}
\hline de los otros & $\begin{array}{l}\text { las demás } \\
\text { matrices } \\
\text { Los que } \\
\text { gestionan el } \\
\text { desarrollo }\end{array}$ & $\begin{array}{l}\text { participación / } \\
\text { sensibilización }\end{array}$ & $\begin{array}{l}\text { publicaciones, etc, la referencia a los } \\
\text { sectores menos reconocidos (boletines } \\
\text { digitales, publicaciones en intranet, etc.) } \\
\text { Generación de encuentros para construir } \\
\text { "Cartografías de actores, relaciones y } \\
\text { acciones" para promover las acciones } \\
\text { conjuntas y múltiples de los trabajos en } \\
\text { equipo }\end{array}$ \\
\hline $\begin{array}{l}\text { diferente } \\
\text { valoración de } \\
\text { los problemas }\end{array}$ & $\begin{array}{l}\text { los que } \\
\text { gobiernan } \\
\text { legislan/ } \\
\text { los que producen } \\
\\
\text { los que } \\
\text { gobiernan } \\
\text { legislan/ }\end{array}$ & $\begin{array}{l}\text { Sensibilizar / } \\
\text { Participar } \\
\text { Información }\end{array}$ & $\begin{array}{l}\text { Generación de espacios de encuentro } \\
\text { entre estas matrices (inauguración de } \\
\text { feria, reuniones para ordenanza de } \\
\text { agricultura familiar, invitación para } \\
\text { exponer en reuniones con productores) } \\
\text { Sistematizar experiencias de Agricultura } \\
\text { Familiar y publicarlas en espacios } \\
\text { académicos y mediáticos. }\end{array}$ \\
\hline
\end{tabular}

\section{El Software IEC: el momento de medir lo vivo}

La carga en el Software IEC de las acciones desarrolladas, permite el seguimiento y monitoreo de la EC facilitando la toma de decisiones en el marco del proyecto. Los informes de visualización autogenerados por el sistema ponen en conexión matrices socioculturales, acciones desarrolladas, procesos comunicacionales promovidos en cada componente de la problemática en un momento determinado. El reconocimiento compartido del avance del cambio social conversacional en marcha genera, además, conversaciones nuevas en el marco del equipo interdisciplinario, que fortalecen la apropiación de otro modo de entender y operar la comunicación como fenómeno histórico y emergente, de creciente complejidad. En este apartado, se presentan algunos informes de visualización generados a partir de la carga en el Software IEC. 


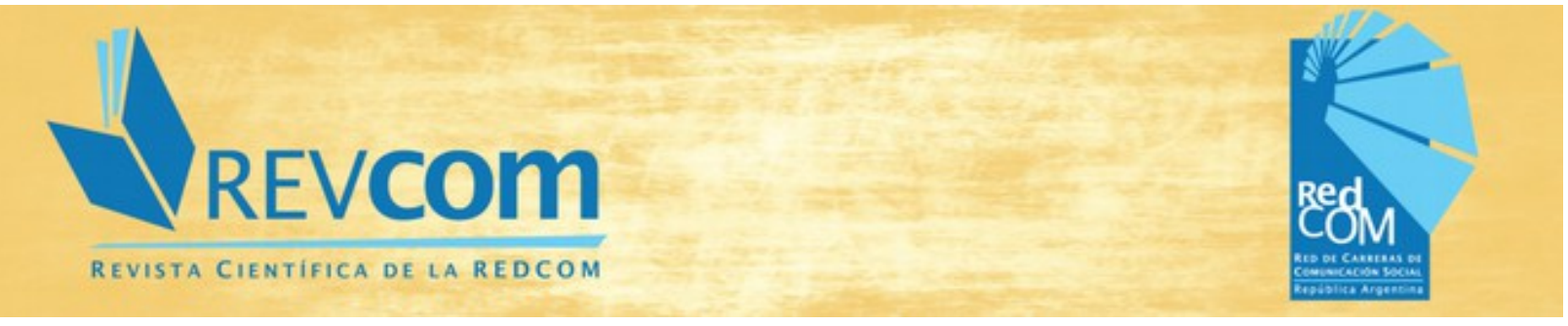

REVCOM | ISSN 2451-7836 | Año 4, \#8 | mayo de 2019 | Contribuciones | e007

Figura 4. Dimensiones comunicacionales por Componente de la VTC

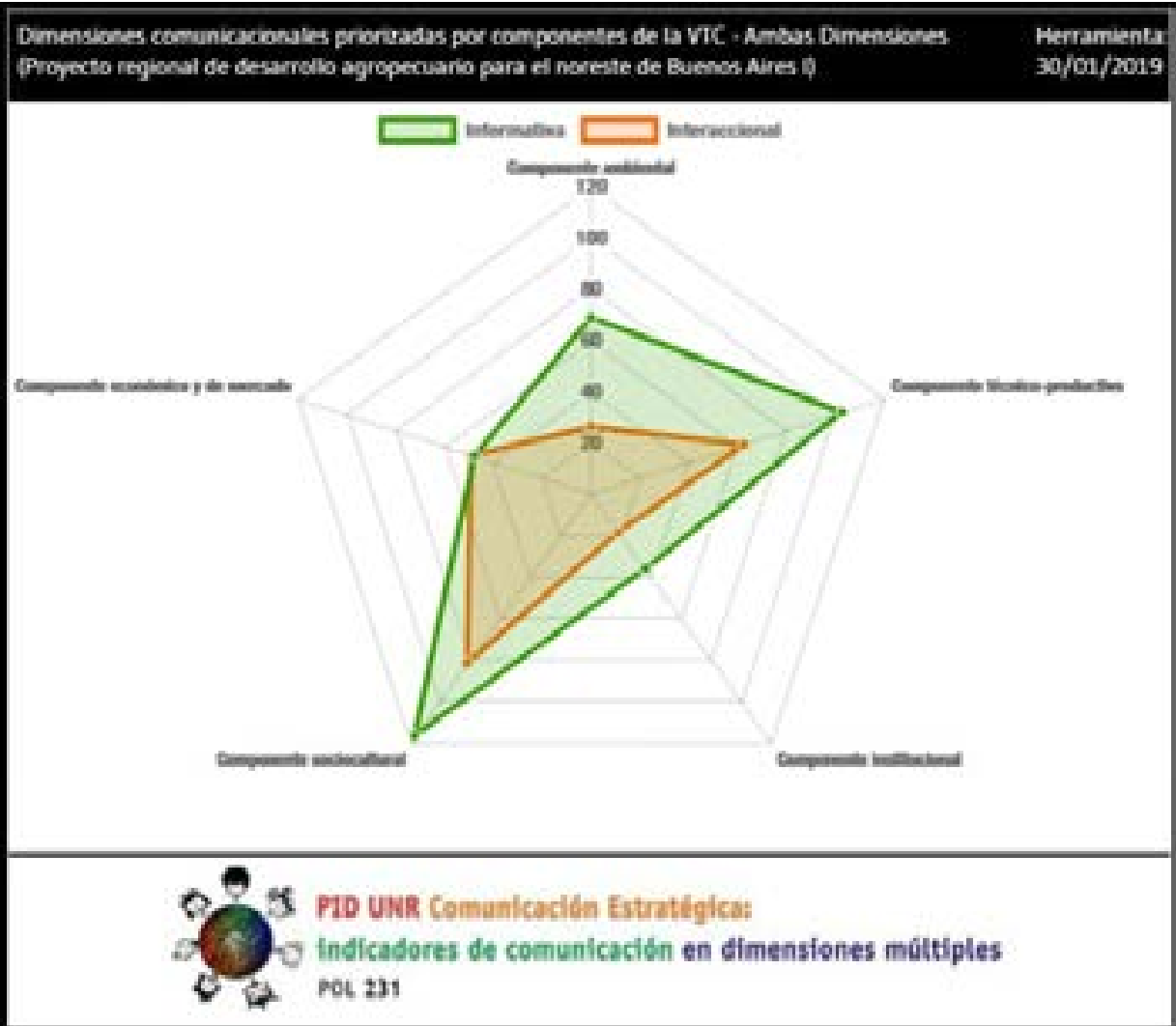

En la Figura 4 se visualiza que los componentes priorizados en la EC fueron el Sociocultural y el Técnico productivo -por sobre el Institucional y el Ambiental-, tanto en la Dimensión Informativa como en la Interaccional. Esta constatación genera conversaciones sobre los aspectos y procesos abordados, y también sobre las ausencias, facilitando el codiseño de la continuidad de la EC.

La Figura 5 muestra el despliegue de las acciones comunicacionales en los aspectos del problema que constituyen el Componente Ambiental. 


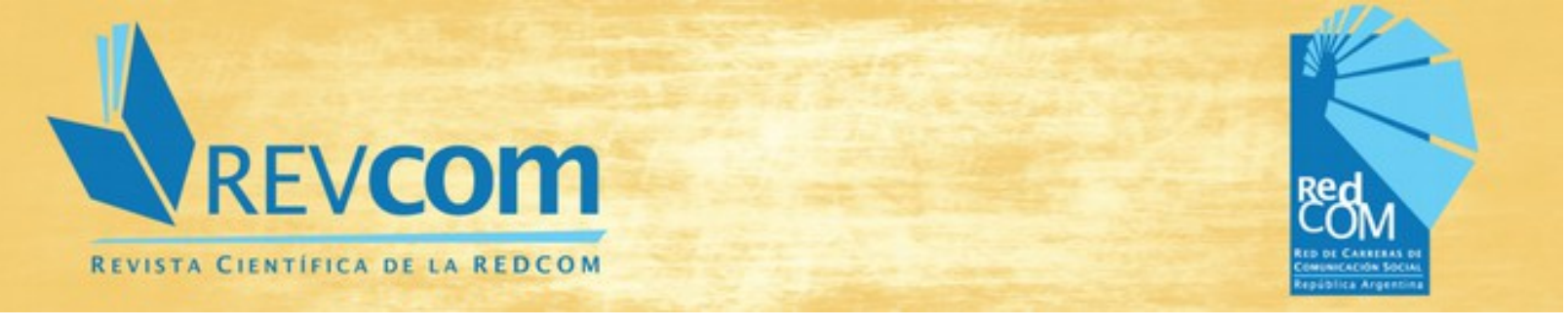

REVCOM | ISSN 2451-7836 | Año 4, \#8 | mayo de 2019 | Contribuciones | e007

Figura 5. Aspectos priorizados por componentes de la VTC en las dimensiones Informativa e Interaccional del Componente Ambiental.

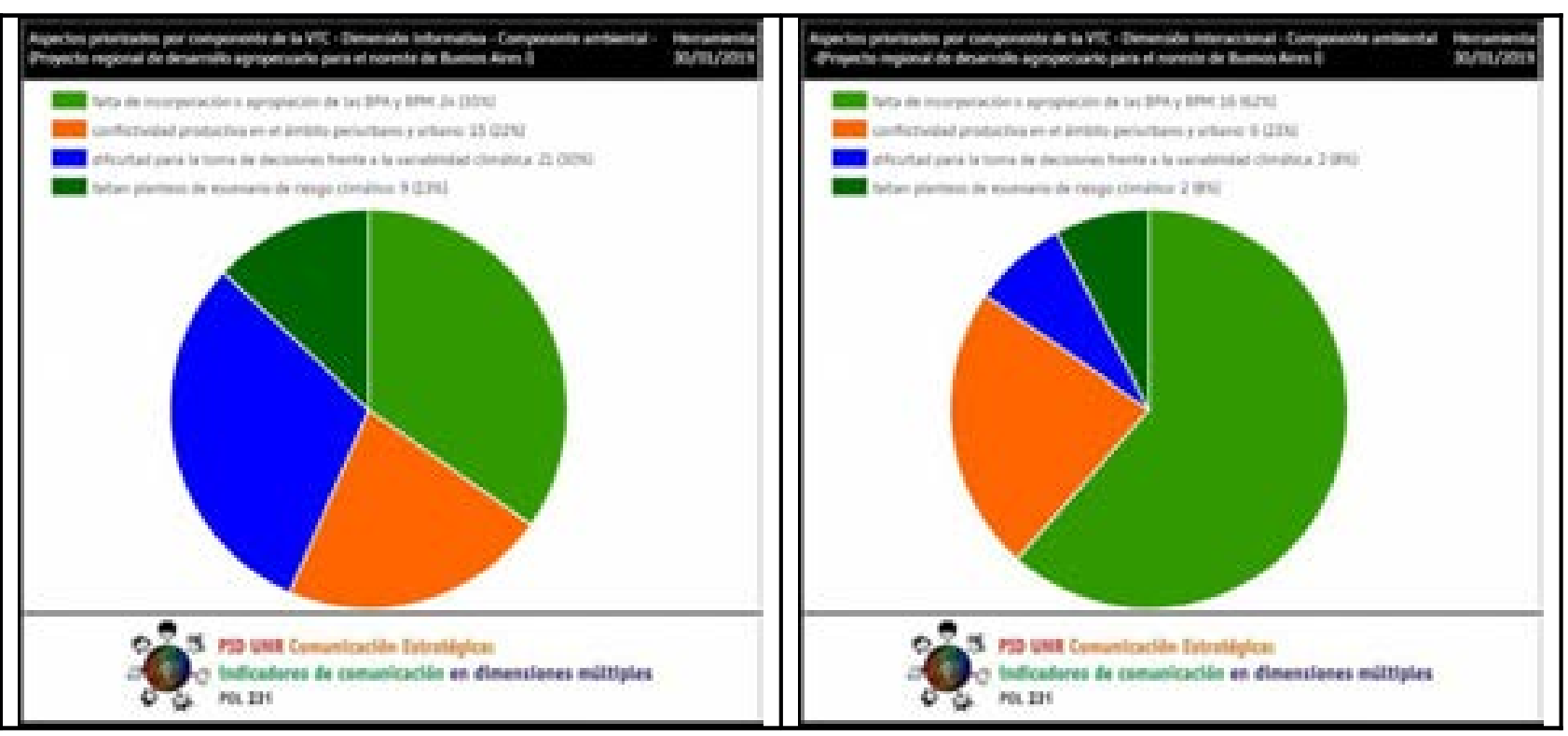

Se visualiza que la mayor proporción de acciones desarrolladas corresponde a la falta de incorporación o apropiación de las buenas prácticas agrícolas y de manufactura, tanto en la dimensión informativa como en la interaccional. Se trata de un aspecto del problema que finalizado el proyecto sigue vigente y aparece entre los principales a abordar a futuro, en virtud de la implementación de normativas. El trabajo sobre este aspecto suele considerarse desde los responsables del sistema de extensión como un punto de partida más acotado y sentido por parte de los actores implicados, que otros que involucran niveles más estructurales de resolución. Este reconocimiento de la parte del problema que resulta más apropiable, ocurre en el análisis compartido del equipo de gestión, a partir de lo que el gráfico trae, mientras se continúa desarrollando la EC.

La Figura 6 muestra las acciones comunicacionales desarrolladas en el Componente Sociocultural. 


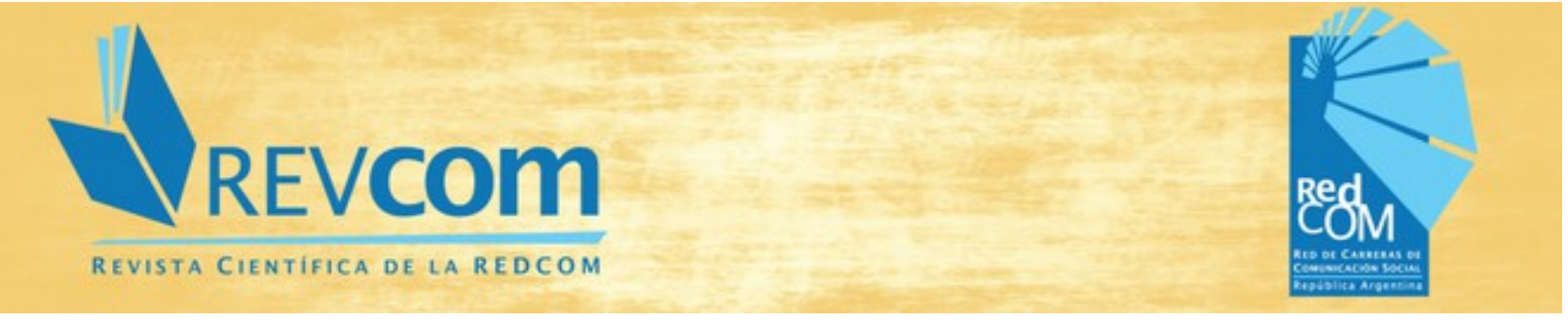

REVCOM | ISSN 2451-7836 | Año 4, \#8 | mayo de 2019 | Contribuciones | e007

Figura 6. Espacios y productos comunicacionales que aportan el Componente Sociocultural.

Dimensiones Informativa (derecha) e Interaccional (izquierda)

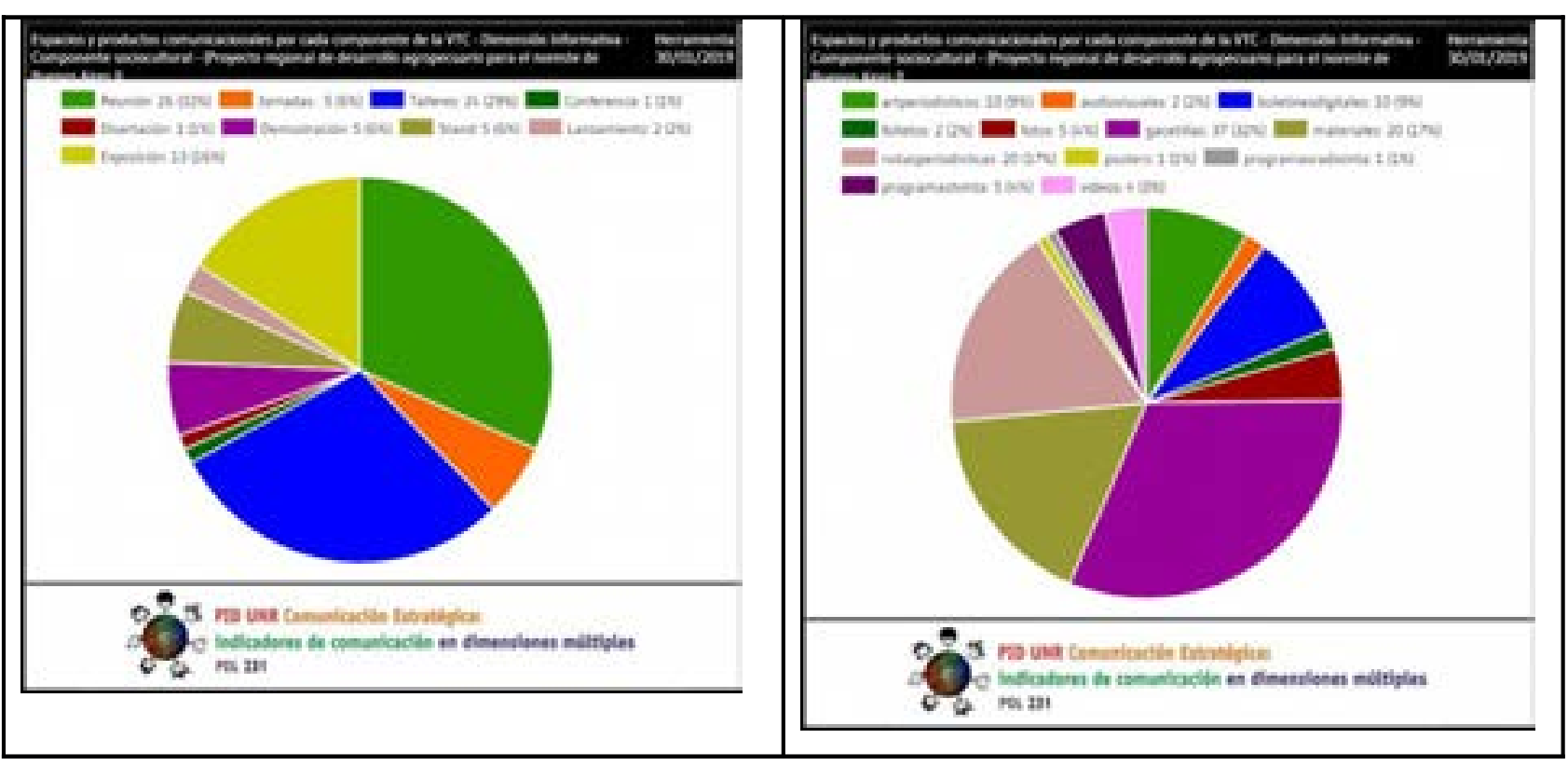

Las reuniones, los talleres y las exposiciones sobresalen en la dimensión interaccional. En este proyecto, el componente sociocultural contiene aspectos centrados en la problemática del reconocimiento de la alteridad y del valor del trabajo del otro, por lo que se priorizaron espacios participativos, de intercambio y construcción conjunta del conocimiento (reuniones, talleres, organización de exposiciones) En la dimensión informativa predominan los formatos vinculados con la prensa gráfica rescatando la diversidad en la producción de los contenidos.

En la figura 7 se accede a otro modo de pensar las acciones y los productos comunicacionales, poniendo foco en los procesos comunicacionales priorizados por componente del problema. 


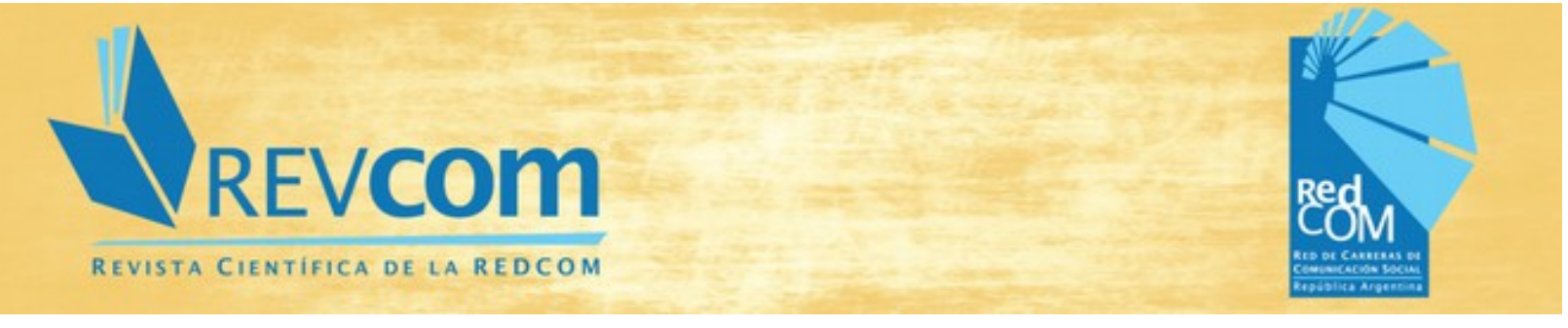

REVCOM | ISSN 2451-7836 | Año 4, \#8 | mayo de 2019 | Contribuciones | e007

Figura 7. Procesos comunicacionales priorizados por componente del problema

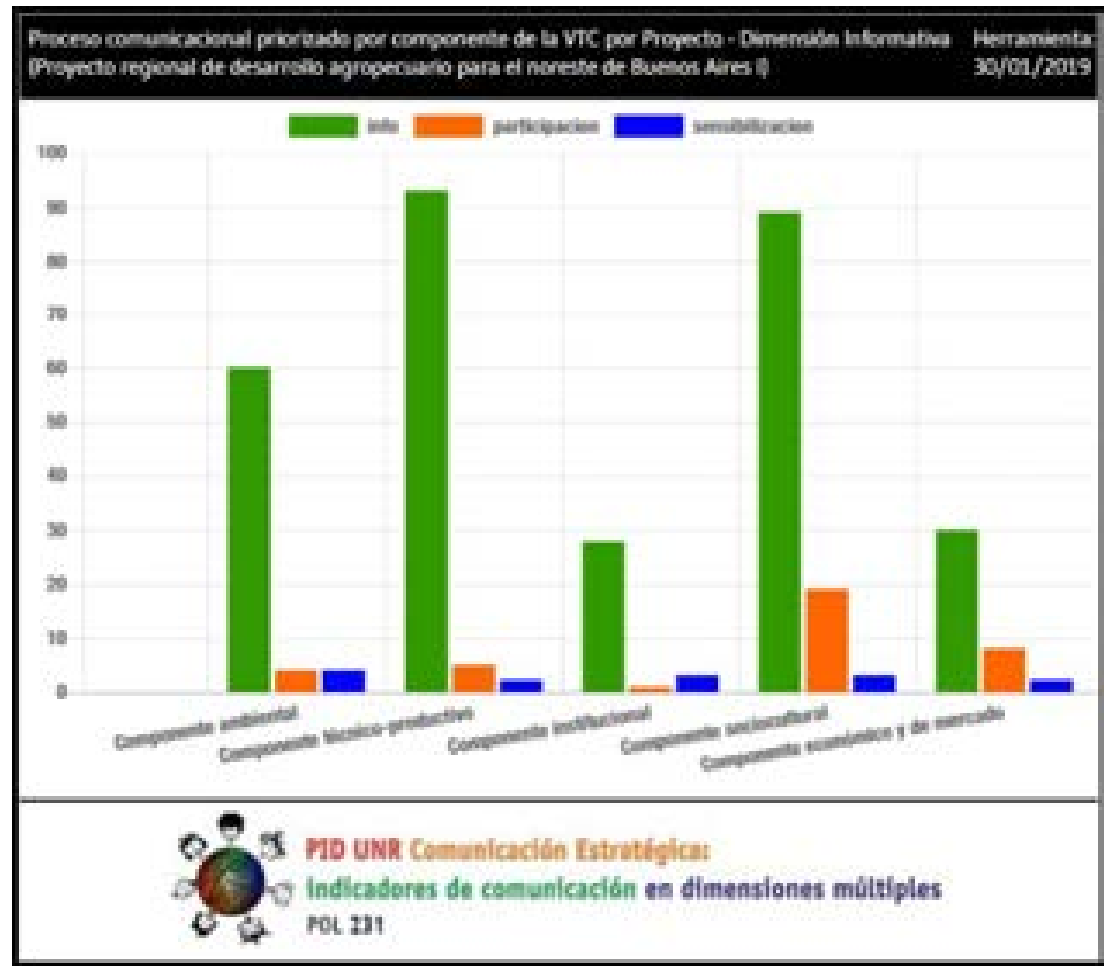

Predominan las acciones vinculadas con la información en todos los componentes del proyecto, con un mayor despegue de los procesos participativos en el componente sociocultural (como se anticipa en la Figura 6), y de la sensibilización en el institucional. Se observa la persistencia de la idea de la información como transformadora de la realidad en las acciones de transferencia. No obstante, el peso relativo de los otros procesos (sensibilización y participación) habilita la revisión de las propias prácticas en el marco del equipo de gestión.

\section{Conclusiones}

Este trabajo da cuenta de la implementación de una IEC incorporando el uso de su software de medición. Describe el ambiente en el que ocurrió su desarrollo a partir del cambio en la modalidad de planificación de la extensión agropecuaria del INTA con el advenimiento de los PRET.

Se comparte la metodología y el producto del despliegue de la Estrategia Comunicacional (EC) en el marco del equipo interdisciplinario del proyecto: Versión Técnica Comunicacional 


\section{VREVCOm \\ REVISTA CIENTIFICA DE LA REDCOM}

REVCOM | ISSN 2451-7836 | Año 4, \#8 | mayo de 2019 | Contribuciones | e007

(VTC) concertada, mapeo comunicacional de actores, reconocimiento y caracterización de Matrices Socioculturales (MS), acciones iniciales propuestas en el Árbol de Soluciones (AS).

Además, se muestran ejemplos del uso del Software IEC en el caso, dando cuenta de algunas de sus potencialidades más interesantes para avanzar en la medición de la comunicación desde lo vivo, "como un tramo más en la exploración de una ciencia fluida", vinculante, que que navega entre, donde objetos y sujetos no son secuencias sino relaciones emergentes (Massoni et al, 2017).

La IEC en este proyecto territorial del INTA muestra avances importantes respecto de los modos tradicionales de incorporación de la comunicación a los proyectos. Entre otros:

- La concertación de una problemática a partir del diálogo de saberes: incorporación de la riqueza de los aportes de las distintas disciplinas, profundidad de la comprensión, consensos para avanzar en fases sucesivas, mayor coherencia en la implementación de acciones comunicacionales.

- La inscripción de las transformaciones buscadas por el proyecto en entornos más complejos y amplios que el de su duración: la posibilidad, entonces, de monitorear los cambios que van aconteciendo e incorporarlos en futuras planificaciones.

- El registro de los indicadores comunicacionales en el devenir del proyecto: como insumo permanente que alimenta la conversación sobre la marcha de la EC, y también como historia comunicacional del proyecto.

A nivel operativo, se reconocen varios aprendizajes a tener en cuenta en futuros proyectos:

- La incidencia de la priorización: la gran variedad de temáticas que involucra un proyecto territorial funciona como un punto a atender en relación a la selección de acciones a desarrollar. En este caso particular, la VTC fue un ordenador clave de la EC. Sin embargo, la realización del Plan Operativo Inicial hubiera contribuido a una organización más consciente en función de las transformaciones buscadas. En la práctica se desplegaron con profundidad algunos aspectos de la problemática y otros quedaron más desatendidos.

- La importancia del registro dinámico: es sabida la ventaja de registrar las acciones comunicacionales mientras suceden. En este caso, la simultaneidad entre el desarrollo del proyecto y del Software IEC dificultó su concreción, restando potencia al seguimiento compartido del proceso. En futuros proyectos sería importante prever la organización de espacios formales sistemáticos para analizar la marcha y realizar ajustes. 


\section{$\bigcup_{\text {REVCOm }}$ \\ REVISTA CIENTIFICA DE LA REDCOM}

REVCOM | ISSN 2451-7836 | Año 4, \#8 | mayo de 2019 | Contribuciones | e007

\section{BIBLIOGRAFÍA}

Instituto Nacional de Tecnología Agropecuaria (2016). Plan Estratégico Institucional 2015-2030: PEI 2015-2030, un INTA comprometido con el desarrollo nacional. 1a ed.- CABA: Ediciones INTA. $56 \mathrm{p}$

Ledesma, S.; Cittadini, E. (2015). Los PRET como instrumento del INTA para aportar al desarrollo territorial en Argentina. En Seminario Internacional: Desarrollo Territorial y Políticas de Innovación. Lecciones aprendidas -13 y 14 mayo 2015 - Rosario, Argentina. Disponible en https://inta.gob.ar/sites/default/files/poster_rosario_2015__pret_del_inta_ledesma_y_cittadini.pdf (Acceso: 28/12/2018)

Mascotti, M.; Spagnolo, L.; Margherit, L.; Piola, M. (2014) "Investigación enactiva: el encuentro en la diversidad como estrategias comunicacionales" en XVII Jornadas nacionales de Extensión Rural y XIX Jornadas de Extensión Rural del Mercosur, 19 al 21 de noviembre de 2014. Zavalla, Santa Fe, Argentina. p 873-885. AADER: Buenos Aires.

Massoni, S. (2018).“'Investigación enactiva en comunicación, metodologías participativas y asuntos epistemológicos" en Revista Latinoamericana de Ciencias de la Comunicación Año XV № 28, ALAIC, enero - junio 2018.

Massoni, S. (2013). Metodologías de la comunicación estratégica. Homo Sapiens Ediciones. Rosario.

Massoni, S. (2012). "Elogio de la comunicación estratégica como algoritmo fluido de la diversidad. Comunicadores a las orillas de otra ciencia y de otra profesión." en Revista Académica Estrategias Año VI № 17, FISEC, Ar URL de la Revista: www.fisec-estrategias.com.ar (Con referato). ISSN 1669- 4015

Massoni, S.; Mascotti, M.; Gerson, E. (2016). Investigación enactiva: una opción frente a los reduccionismos del plan de comunicación estratégica en las organizaciones. Actas de Periodismo y Comunicación, Vol. 2, N. 1, diciembre. La Plata, Argentina. Disponible en http://perio.unlp.edu.ar/ojs/index.php/actas/article/view/4148/3372 (Acceso: 28/12/2018)

Massoni, S. (2016). Avatares del comunicador complejo y fluido. Del perfil del comunicador social y otros devenires. (216 páginas) Ediciones Ciespal. Quito, Ecuador, abril 2016. ISBN 978-997855-141-7

Massoni, S.; Piola, M.; Mascotti, M.; Margherit, L.; Spagnolo, J.; Gerson, E.; Menarvino, B. (2016). Medir la comunicación desde lo vivo. Indicadores comunicacionales en dimensiones múltiples. Editorial UNR: Rosario.

"Estrategia comunicacional de un proyecto territorial. La Investigación Enactiva Comunicacional (IEC) en el INTA, caso San Pedro-Baradero" | Mariana Piola y Mariana Mascotti | https://doi.org/10.24215/2451-7836e007 | Pág. 21 
REVCOM | ISSN 2451-7836 | Año 4, \#8 | mayo de 2019 | Contribuciones | e007

Scala, M.R.; Mascotti, M.; Gaudiño, M. (2018). Territorio en movimiento Dando cuenta del andar de un PRET en el centro de Santa Fe. Rafaela, Argentina. Ediciones INTA. Disponible en https://inta.gob.ar/sites/default/files/inta_rafaela_territorio_en_movimiento.pdf ( A c c e s o : 28/12/2018)

Varela, Francisco (1988). Conocer: tendencias y perspectivas. Cartografía de las ideas actuales. Ed. Gedisa, Barcelona, España. 